\title{
Improvement of Thermal Performance of Electric Vehicle Battery Pack with Phase-change Material
}

\author{
Amarnathvarma Angani, ${ }^{1}$ Euisong Kim, ${ }^{2}$ and Kyoojae Shin ${ }^{1 *}$ \\ ${ }^{1}$ Department of ICT Creative Design, Busan University of Foreign Studies, Busan 46234, Republic of Korea \\ ${ }^{2}$ Department of Robotics Engineering, Busan University of Foreign Studies, Busan 46234, Republic of Korea
}

(Received October 25, 2019; accepted March 9, 2020)

Keywords: thermal performance, sensors, electric vehicles, lithium polymer pouch battery, phase-change material, discharge

In this study, we analyzed the thermal performance of electric vehicle lithium batteries with phase-change materials (PCMs) at $26{ }^{\circ} \mathrm{C}$. PCMs and temperature sensors are the major factors affecting the thermal performance. To improve the heat transfer rate of PCMs in a lithium polymer pouch battery with 16 Ah capacity, a battery thermal management system with different PCMs, namely, RT15, RT31, EG5, and EG26, is proposed and experimentally investigated. The results show that the temperature of the battery surface without PCMs increased to $35.9{ }^{\circ} \mathrm{C}$ at different discharge rates at a room temperature of $25{ }^{\circ} \mathrm{C}$. In the case of the battery with EG26, its surface temperature was $30.5{ }^{\circ} \mathrm{C}$, which shows a temperature difference of $5.4{ }^{\circ} \mathrm{C}$ from the battery without a PCM. A low temperature-rise rate and a uniform temperature distribution were observed in the batteries with PCMs. In addition, a numerical simulation using the computational fluid dynamics software FLUENT was also carried out. The numerical simulation results are in good agreement with experimental data, such as the temperatures of batteries monitored with sensors.

\section{Introduction}

The demand for electric vehicles (EVs) has been increasing, and lithium batteries are required for high power generation. However, batteries in EVs generate much heat. ${ }^{(1)}$ Many researchers have developed various battery thermal management systems (BTMSs) that can meet various requirements, such as high power, high charging rate, and improved driving performance. Referring to the literature, the BTMSs can be broadly divided into two categories: active and passive cooling systems. The active cooling system involves the forced circulation of cool air and water. ${ }^{(2)}$ Air cooling can cool the EVs under normal operating conditions, but the battery temperature will be high under high charging and discharging conditions. Modified battery designs, for example, by changing the battery position, adding a guide plate, and changing the entrance angle, have been proposed; however, air cooling remains insufficient. ${ }^{(3,4)}$ A liquid or water cooling system is better than those of EVs with air cooling designs but the setup is complex, which will increase the complexity and weight of the vehicle. ${ }^{(5-7)}$

*Corresponding author: e-mail: kyoojae@bufs.ac.kr

https://doi.org/10.18494/SAM.2020.2695 
The phase-change material (PCM) cooling system is the best alternative to the abovementioned thermal management systems. No pump or blower is required in this PCM cooling system; hence, it is cost-effective and simple in design and construction. The excess heat generated by the batteries of an EV is absorbed by the PCMs close to the cell in the battery module. If the temperature of the battery reaches the melting point of the PCM, heat will be stored as latent heat, thus minimizing the temperature increase. ${ }^{(8-10)}$

PCMs undergo a phase change upon absorbing or releasing the excess heat from the battery. This passive PCM cooling mechanism can maintain the operating temperature of batteries within a relatively constant temperature range. With this mechanism, PCMs are the best option for the effective thermal management of EV batteries by maintaining a uniform temperature distribution under any extreme weather conditions. Zhao et al. ${ }^{(11)}$ studied different batteries of thermal management systems, and they concluded that PCMs are very effective for such systems. Karimi et al. ${ }^{(12)}$ experimentally studied thermal management systems using cylindrical lithium ion batteries with composite PCMs, and they found that metal matrixPCM composites decrease the maximum $\Delta T$ (temperature gradient on battery surface) between the battery surface and the composite PCMs by up to $70 \%$. Lyu et al. ${ }^{(13)}$ proposed a thermal management system for a $\mathrm{LiFePO}_{4}$ battery pack with a composite $\mathrm{PCM}$ and aluminum wire mesh plates, and they obtained the decreases in the maximum temperature of the battery surface by 19,21 , and $26 \%$ at $1 \mathrm{C}, 2 \mathrm{C}$, and $3 \mathrm{C}$ discharge rates, respectively. Moreover, the low thermal conductivity restricts their use of the PCM-based thermal management system in required applications. $^{(14)}$ A low-composite PCM (L-CPCM) coupled with a low-fin thermal management system was proposed. From the results of the experiment, it was concluded that a temperature difference of $3.6{ }^{\circ} \mathrm{C}$ was obtained with expanded graphite composite PCMs. ${ }^{(15)}$

Rao et al. ${ }^{(16)}$ experimentally used paraffin/copper foam for the thermal management of a $10 \mathrm{Ah} \mathrm{LiFePO}_{4}$ battery. The battery without a PCM showed a temperature of $40.84{ }^{\circ} \mathrm{C}$, whereas that with a PCM showed a temperature drop of $3.24{ }^{\circ} \mathrm{C}$. When the ambient temperature was $33{ }^{\circ} \mathrm{C}$, the maximum temperature of the battery without a $\mathrm{PCM}$ was $42{ }^{\circ} \mathrm{C}$, and the temperature difference between cells was $4{ }^{\circ} \mathrm{C}$.

Ling et al. ${ }^{(17)}$ proposed a hybrid active cooling system that can improve the thermal performance of a thermal management system. They showed that a maximum temperature difference of $5.4{ }^{\circ} \mathrm{C}$ was observed with RT44 or a commercial PCM.

In this study, a PCM-based partially passive thermal management system was developed for lithium polymer pouch battery packs to improve the thermal performance of batteries. The main aim is to remove or decrease the excess temperature of the battery module by using a PCM. The specific objectives are as follows.

1. Identify temperature changes in the battery with temperature sensors.

2. Maintain the battery temperature of a module under safe operating conditions through the use of PCMs.

3. Design and propose a single lithium polymer pouch battery with a PCM thermal management system.

4. Conduct the numerical simulation of the proposed model of the battery module with different PCMs. 
5. Compare the simulation results of voltage drop and temperature distribution on the surface at different discharge rates.

6. Identify the best PCM on the basis of simulation results.

7. Devise an experimental setup and run an experiment with the proposed PCMs at different discharge rates of the battery on the basis of simulation results.

8. Repeat the experiment under the same discharge and temperature conditions using different PCMs.

9. Compare results and identify the best PCM to satisfy the designed specifications and maintain the thermal performance of the battery under the same operating temperature limits.

\section{Thermal Battery Modeling}

The pouch battery is made of a lithium polymer material with the dimensions of $220 \times 132 \times 7.8 \mathrm{~mm}^{3}$ (width, length, and thickness) and a rated capacity of $3.7 \mathrm{~V} / 16 \mathrm{Ah}$. Thermocouples were attached to each battery to monitor the temperature. Four battery modules were electrically connected in series. A schematic representation of the proposed battery module for the thermal management of lithium polymer pouch batteries is shown in Fig. 1. Sensors are connected to each battery surface and on the outside surface of PCMs.

Under discharging conditions, the temperature on the battery surface increases gradually. Hence, to detect these changes in battery temperature, thermocouples as sensors were attached to the battery and PCM surface. The specifications of the battery module are shown in Table 1.

For free convection in the experiment, the governing equations of the conservation of mass, energy, and momentum are given as follow. ${ }^{(18)}$

Conservation of mass:

$$
\frac{\partial v}{\partial y}+\frac{\partial \omega}{\partial z}=0
$$

where $v$ and $\omega$ are the velocities in the $y$ and $z$ directions.

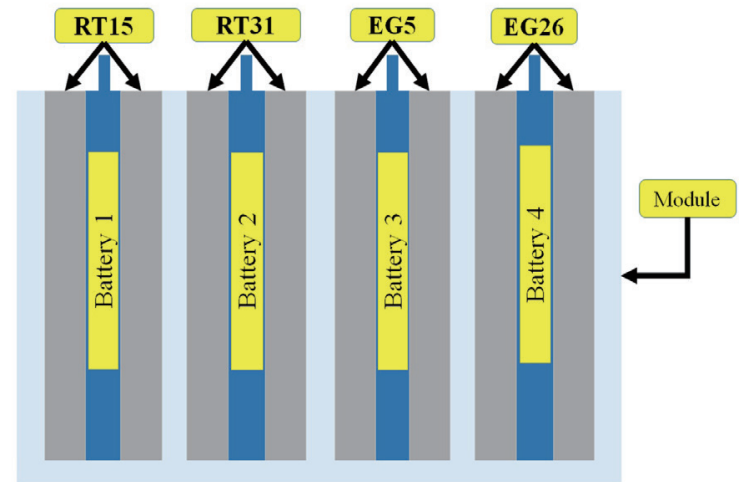

Fig. 1. (Color online) Schematic representation of setup with sensors.
Table 1

Battery specifications.

\begin{tabular}{lc}
\hline Name & Parameters \\
\hline Cell type & Li polymer \\
Module nominal voltage $(\mathrm{V})$ & $3.7 \mathrm{~V}$ \\
Module nominal capacity $(\mathrm{Ah})$ & 16 \\
Max discharge current $(\mathrm{A})$ & $48(3 \mathrm{C})$ \\
Max charge current $(\mathrm{A})$ & $128 \mathrm{~A}(15 \mathrm{C})$ \\
Operating temperature range $\left({ }^{\circ} \mathrm{C}\right)$ & $-20-60$ \\
Charging temperature range $\left({ }^{\circ} \mathrm{C}\right)$ & $0-45$ \\
\hline
\end{tabular}


Conservation of momentum:

$$
\frac{\partial(\rho v)}{\partial t}+\nabla(\rho \mu v)=\nabla(\mu \Delta v)-\frac{\partial p}{\partial y}+s_{y} \frac{\partial(\rho \omega)}{\partial t}+\nabla(\rho \mu w)=\nabla(\mu \Delta \omega)-\frac{\partial p}{\partial z}+s_{z}+s_{b}
$$

where $\rho$ is the density, $p$ is the pressure, $\mu$ is the liquid viscosity, and $s_{y}, s_{z}$, and $s_{b}$ are the source terms.

The energy equation is given as

$$
\frac{\partial(\rho h)}{\partial t}+\nabla(\rho \mu h)=\nabla(\alpha \Delta h)-s_{h}=0
$$

where $\alpha$ is the thermal diffusivity and $s_{h}$ is the source term. Heat is generated from the battery and conducted through the pouch battery and PCMs.

The equation for heat generation in the battery is given as

$$
Q=m c_{p} \Delta T
$$

where $m$ is the mass of the cell, $c_{p}$ is the specific heat of the cell, and $\Delta T$ is the temperature gradient on the battery surface.

The heat conduction or energy balancing equation is given as

$$
c_{p} \frac{\partial T}{\partial x}+c_{p} \frac{\partial T}{\partial y}=k_{x} \frac{\partial T}{\partial x}+k_{y} \frac{\partial T}{\partial y} .
$$

\section{Simulation of Thermal Lithium-polymer Pouch Battery}

\subsection{Heat generation}

The proposed model was designed using AUTOCAD with the pouch surrounding the lithium polymer battery. In the numerical study, the mesh consisted of 50532 elements. The mesh was finely refined by the refinement method, where there were contact regions with small thicknesses. The PCMs were incorporated around the battery as shown in Fig. 2. The mode of heat transfer was free convection. The module was subjected to conjugate heat transfer. The generated heat was transferred to reach a room temperature of $25^{\circ} \mathrm{C}$, and the battery initial temperature was $26.1^{\circ} \mathrm{C}$. The internal cell surfaces and other components were coupled with the boundary conditions that satisfied the continuity of temperature profiles at the boundary line. This coupling was applied to both terminals of the battery module. The thermophysical properties of PCMs are shown in Table 2.

In a simulation to evaluate the performance of PCM, the following assumptions are considered: free convection in heat transfer, constant battery thermal conductivity, average specific heat, radiation effects, and zero contact resistance. In the present work, the only heat- 


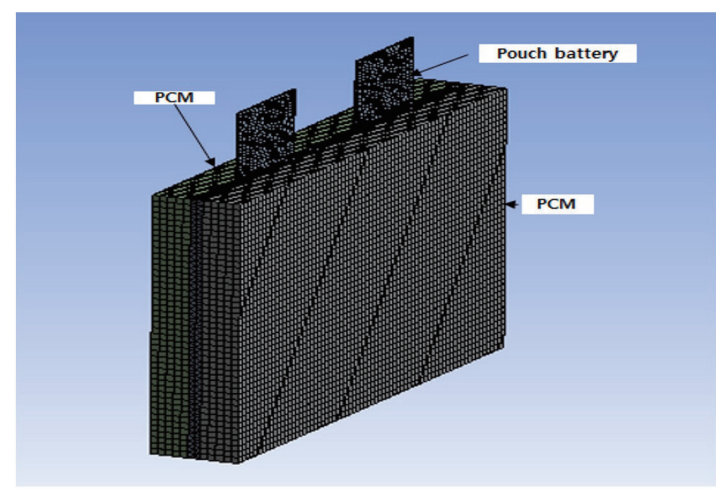

Table 2

Thermophysical properties of PCMs.

\begin{tabular}{lcc}
\hline PCM & $\begin{array}{c}\text { Melting point } \\
\left({ }^{\circ} \mathrm{C}\right)\end{array}$ & $\begin{array}{c}\text { Thermal conductivity } \\
(\mathrm{W} / \mathrm{mK})\end{array}$ \\
\hline RT15 & 15.0 & 0.2 \\
RT31 & 31.0 & 0.2 \\
EG5 & 5.0 & 7.0 \\
EG26 & 26.0 & 2.5 \\
\hline
\end{tabular}

Fig. 2. (Color online) Modeling of proposed Li polymer pouch battery BTMS.

generating component is the battery, whose amount of heat generated depends on the discharge rate.

The general energy balance equation is considered as

$$
q=I\left(u-v-T \frac{d u}{d t}\right)=h_{s} A\left(T-T_{a m b}\right)+M_{c e l l} c_{p} \frac{d T}{d t},
$$

where $I$ is the battery operating current, $u$ and $v$ are the open circuit potential and battery operating potential, respectively, $T$ is the battery operating temperature, $C_{p}$ is the specific heat of the cell, $h_{s}$ is the heat transfer coefficient, $A$ is the area of the battery, $T_{a m b}$ is the ambient temperature of the cell, and $M_{\text {cell }}$ is the mass of the cell. The governing equation is the sum of Gibbs free energy, electric work, and entropy generation,

$$
Q=\Delta G+W_{\text {ele }}+T \Delta s
$$

where $G$ is the Gibbs free energy and $s$ is the entropy.

\subsection{Finite volume method}

The finite volume method is used to discretize the governing equation. The partial differential equation [Eq. (8)] consists of the transient term, diffusion term, and a source term:

$$
\frac{\partial}{\partial x}(\rho \theta)+\nabla\left(\rho \vec{u} \theta-\Gamma_{\theta} \nabla_{\theta}\right)=s_{\theta},
$$

where $\theta$ is considered 1 and 0 for the energy and continuity equations, respectively, $\Gamma_{\theta}$ is the diffusion coefficient, and $s_{\theta}$ is the source term. According to the experimental setup, the PCM melted zone is defined and restricted by the battery surface, and there is no flow circulation in 
this domain. The thermal energy equation is analyzed and discretized as follows; the equation is assumed and considered only in two dimensions, that is, in the $x$ and $y$ directions. ${ }^{(19)}$

$$
\frac{\partial}{\partial t}\left(\rho c_{p} T\right)+\frac{\partial}{\partial x}\left(\rho u c_{p} T\right)+\frac{\partial}{\partial y}\left(\rho v c_{p} T\right)=\frac{\partial}{\partial x} k\left(\frac{\partial T}{\partial x}\right)+\frac{\partial}{\partial y} k\left(\frac{\partial T}{\partial y}\right)+s_{h}
$$

To determine the temperature, the source term in the governing energy equation includes the amount of latent heat absorbed during the phase change process at a control volume, where $s_{h}$ is the source heat term and $\rho$ is the density of the entire cell zone, where the volumetric heat source is constant. However, in the PCM, heat is not generated and only melting and solidification occur. The viscosity of the solid zone increases, similarly to the porous medium behavior in the mushy zone (melting zone).

The linear source term and linear liquid fraction terms are assumed for the melted or solidified interface. This gives an effective porosity of 0.5 . To obtain this output, the liquid fraction can be expressed as

$$
\beta=\frac{\Delta H}{H},
$$

where $H=h+\Delta H$, with the specific enthalpy as

$$
\Delta h=h_{r e f}+\int_{T_{r e f}}^{T} c_{p} d T .
$$

The liquid fraction can become 0 or 1 when temperatures are greater or smaller than the melting temperature:

$$
\beta=0, T>T_{m}, \beta=1, T<T_{m} .
$$

\subsection{Simulation results}

Under the simulation conditions, the initial battery temperature was $26.1{ }^{\circ} \mathrm{C}$ and the room temperature was $25{ }^{\circ} \mathrm{C}$. When the batteries were subjected to discharge for $30 \mathrm{~min}$, the battery temperature reached $35.9{ }^{\circ} \mathrm{C}$ without PCMs. After applying a load, the temperature distribution was observed in the batteries. The simulation results of the batteries are shown in Figs. 3(a)-3(e); temperature distributions in the batteries with and without PCMs were compared. With PCMs, the temperature of the battery surface was low. The simulation results of the batteries with and without PCMs are also shown in Table 3. 


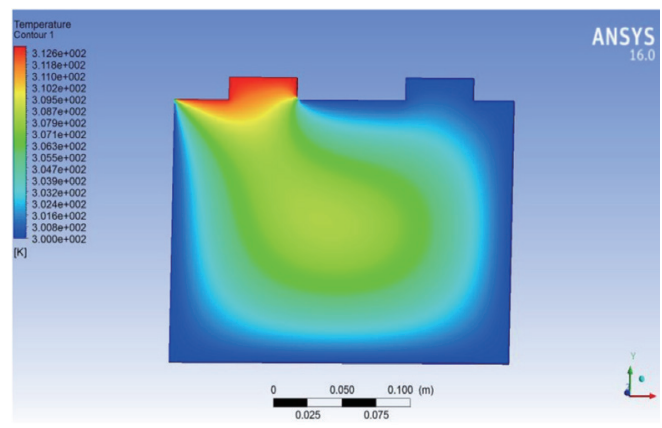

(a)

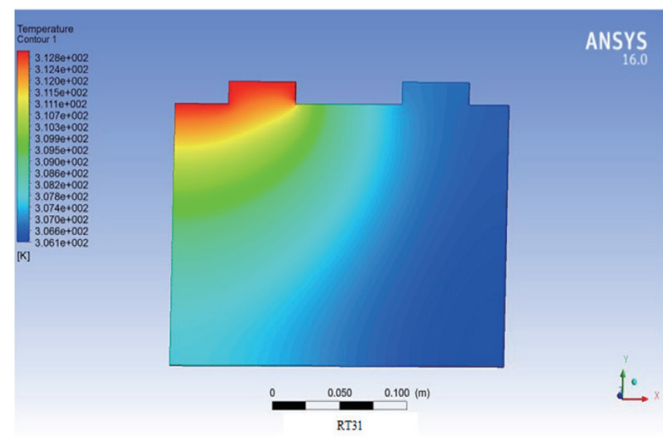

(c)

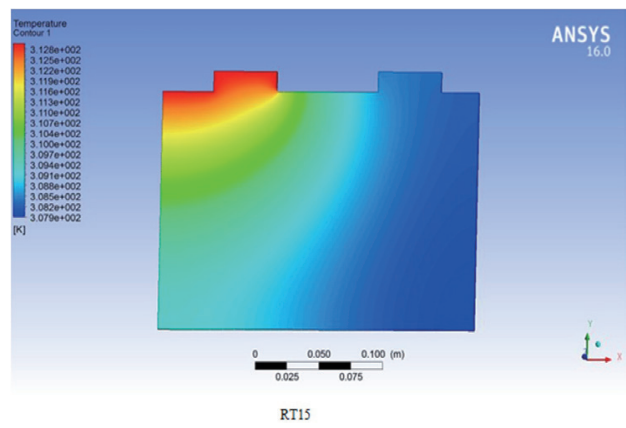

(b)

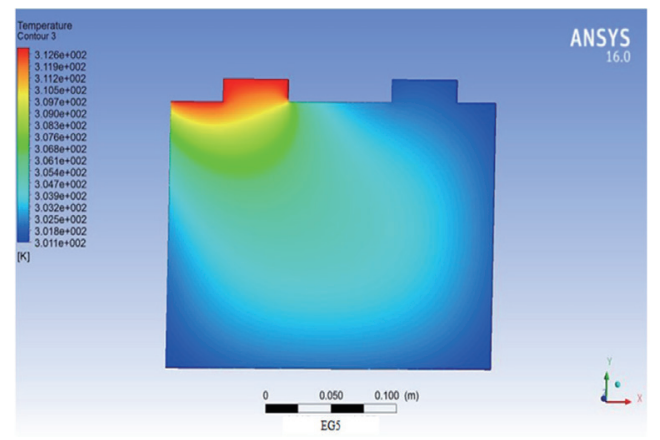

(d)

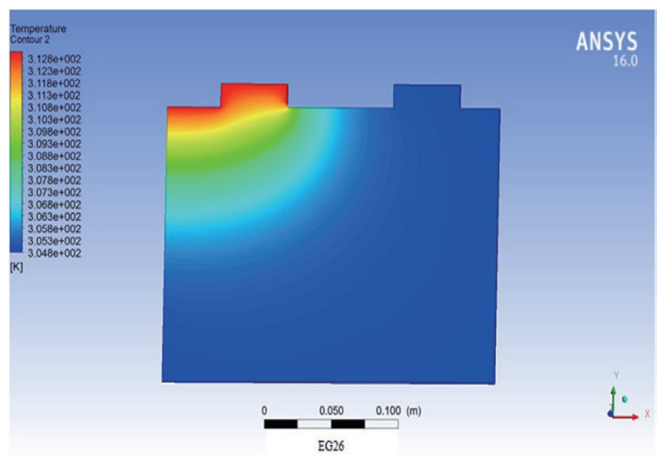

(e)

Fig. 3. (Color online) Simulation results of proposed BTMS design: temperature profiles for (a) battery without PCM, (b) battery with RT15, (c) battery with RT31, (d) battery with EG5, and (e) battery with EG26.

Table 3

Simulation results of batteries with and without PCMs.

\begin{tabular}{lcc}
\hline PCM & $\begin{array}{c}\text { Thermal conductivity } \\
(\mathrm{W} / \mathrm{mK})\end{array}$ & $\begin{array}{c}\text { Maximum battery } \\
\text { surface temperatures }\left({ }^{\circ} \mathrm{C}\right)\end{array}$ \\
\hline None & 0.02 & 35.9 \\
RT15 & 0.2 & 33.3 \\
RT31 & 0.2 & 32.2 \\
EG5 & 7.0 & 31.6 \\
EG26 & 2.5 & 31.3 \\
\hline
\end{tabular}




\section{Experimental Results and Discussion}

\subsection{Experimental methodology}

The experimental setup consisted of four battery modules placed inside an aluminum container one after the other, as shown in Fig. 4. All four batteries were mounted on a common base and had four different PCMs closely packed on both sides of each battery.

The temperature sensors were attached as shown in Fig. $5 ; T_{1}, T_{2}, T_{3}$, and $T_{4}$ were attached to the front and back of batteries. The excess temperatures were measured with sensors $T_{5}, T_{6}$, $T_{7}$, and $T_{8}$ placed on the front and back of the PCMs. Battery1, battery2, battery3, and battery 4 were closely attached to RT15, RT31, EG5, and EG26, respectively. All these batteries were electrically connected in series for charging and discharging. The sensors were attached to the battery and PCM outer surfaces to monitor temperature variations.

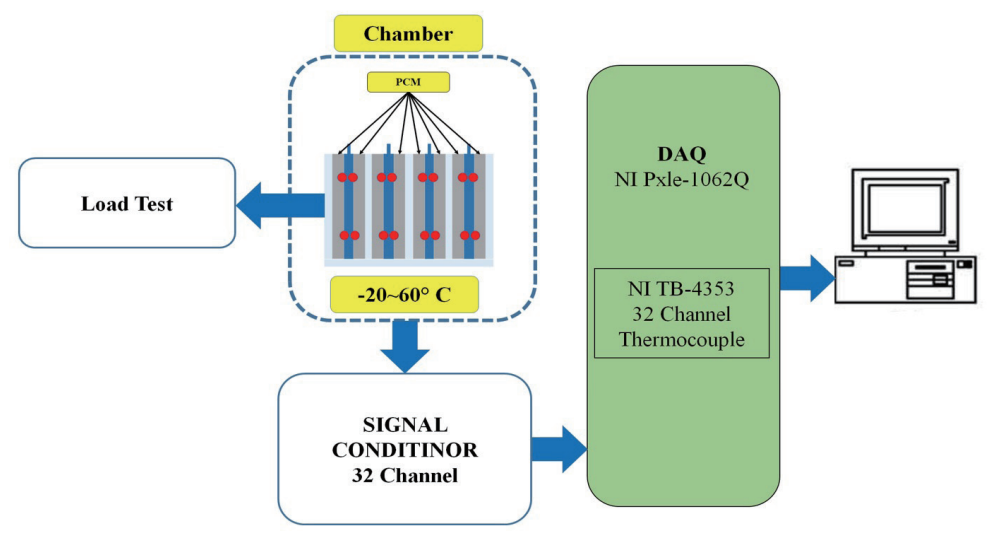

Fig. 4. (Color online) Schematic representation of experimental setup.

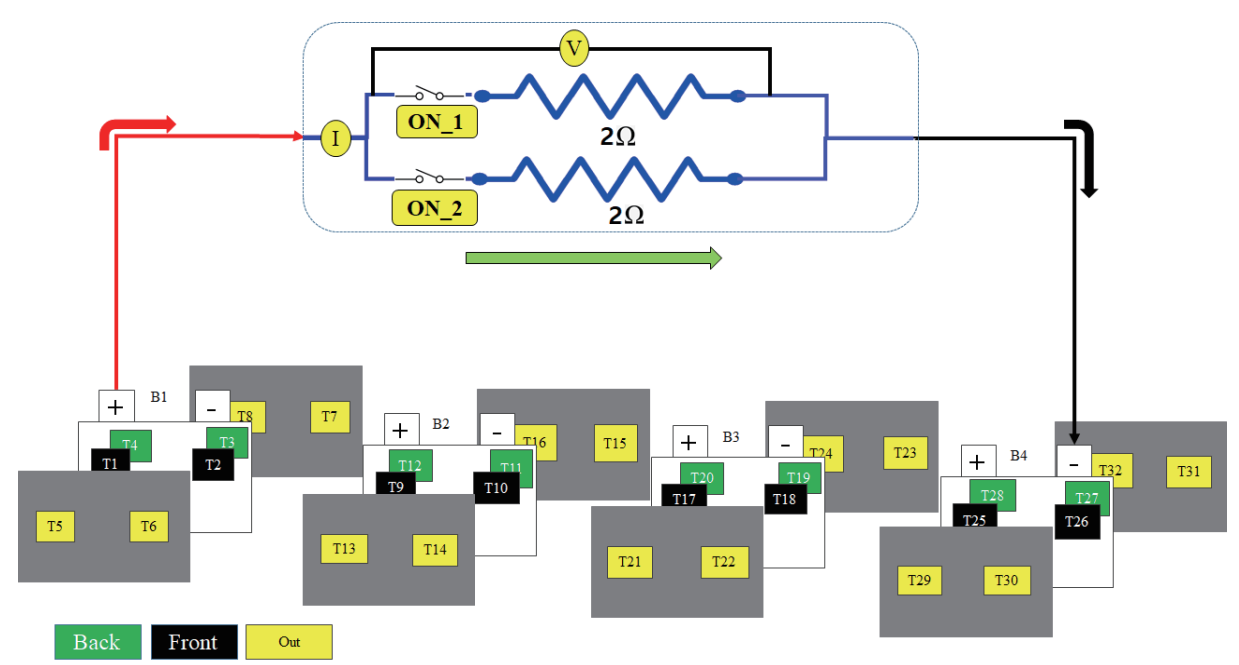

Fig. 5. (Color online) Schematic representation of sensors on BTMS. 
The temperature sensors after their calibration were connected to the signal conditioner. Also, the National Instrument Data Acquisition (NI DAQ) (NI Pxle) was connected to the signal conditioner from one side, and the other side of the DAQ was connected to a computer monitor to display the temperature variations in each battery connected to the load discharge unit, as shown in Fig. 6. ${ }^{(20)}$ The thermal conductivities of EG5/26 and RT15/31 PCMs with the dimensions of $115 \times 220 \mathrm{~mm}^{2}$ were measured. The thermal conductivities of EG5, EG26, RT31, and RT15 were 7.0, 2.5, 0.2, and $0.2 \mathrm{~W} / \mathrm{mK}$, respectively, as in the data sheet provided by the manufacturer.

The experimental results are shown in Figs. 7(a)-7(d). Figures 7(c) and 7(d) show that the maximum battery temperature without PCMs is $35.9{ }^{\circ} \mathrm{C}$, and with EG26 and EG5 PCMs, the

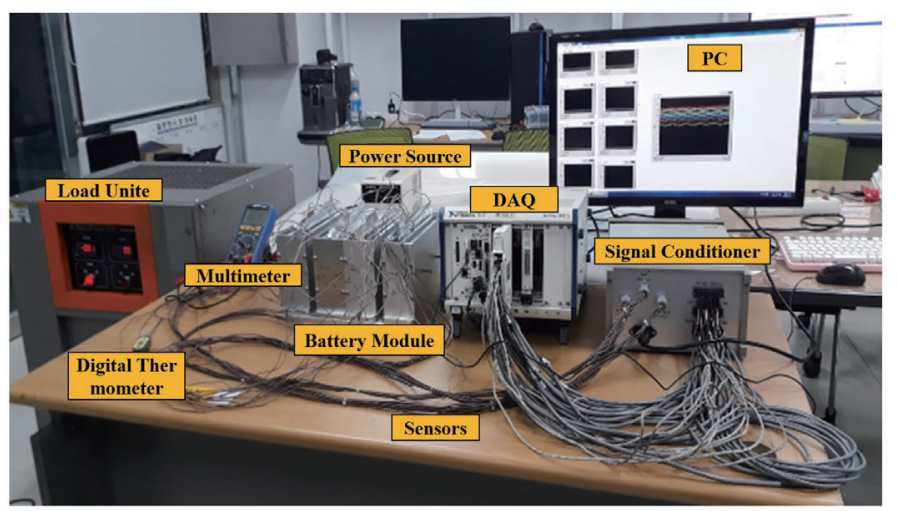

Fig. 6. (Color online) Experiment setup of BTMS.

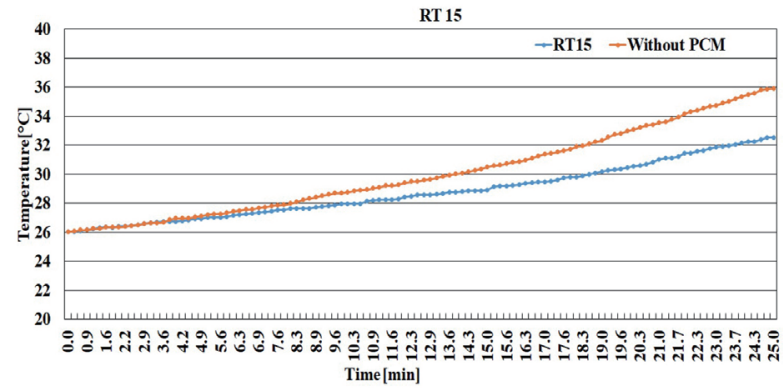

(a)

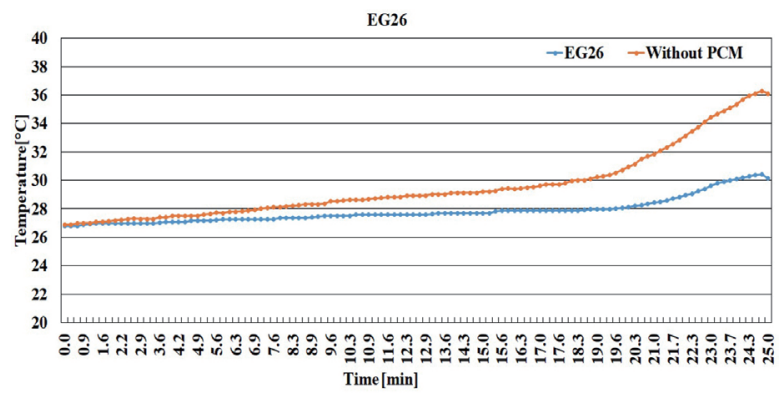

(c)

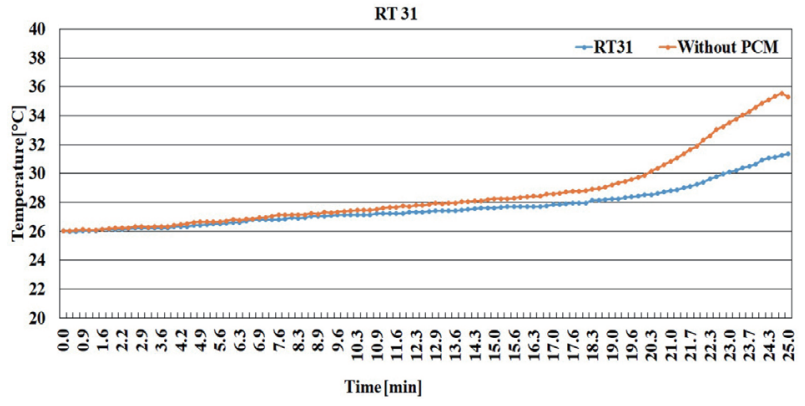

(b)

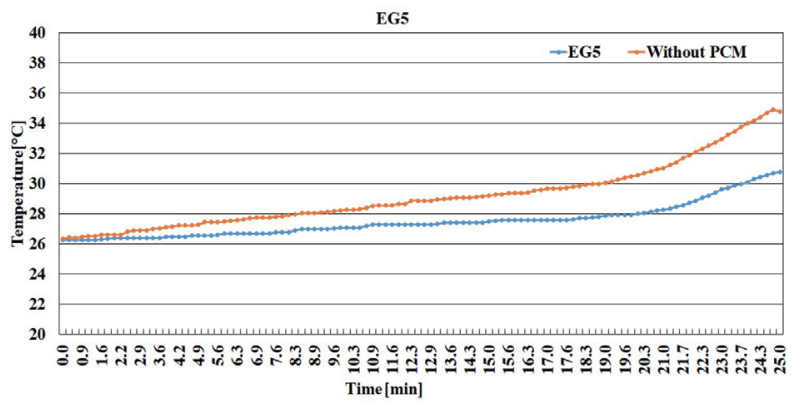

(d)

Fig. 7. (Color online) Maximum temperature drop for batteries with and without PCM: (a) RT15, (b) RT31, (c) EG5, and (d) EG26. 
maximum battery temperatures are 30.7 and $30.5{ }^{\circ} \mathrm{C}$, respectively. These results show that the battery performance is tremendously improved, and better thermal management of the pouch battery is achieved. The temperature drop of each PCM during discharge is shown in Fig. 8.

As shown in Fig. 9, for comparison between batteries with and without PCMs, we considered "no PCM" as the atmospheric air condition, and hence the thermal conductivity of air was taken to be $0.02 \mathrm{~W} / \mathrm{mK}$. To improve the thermal management system in batteries, various thermal parameters, such as heat transfer and thermal conductivity, were compared between batteries with and without PCMs. The maximum temperatures in the batteries with and without PSMs are shown in Fig. 9(a). The maximum temperature difference between batteries with and without PCMs are shown in Fig. 9(b). Among all PCMs, EG26 showed the maximum temperature difference of $5.4{ }^{\circ} \mathrm{C}$. Figure 9(c) shows the heat transfer between the PCM and the battery surface.

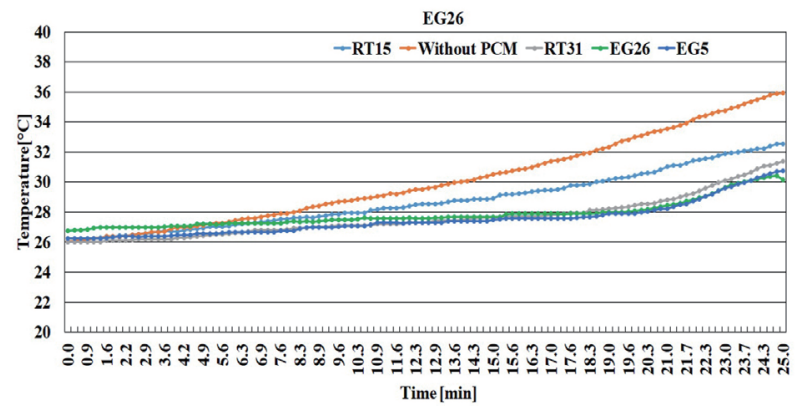

Fig. 8. (Color online) Temperature drop in batteries with and without PCM.

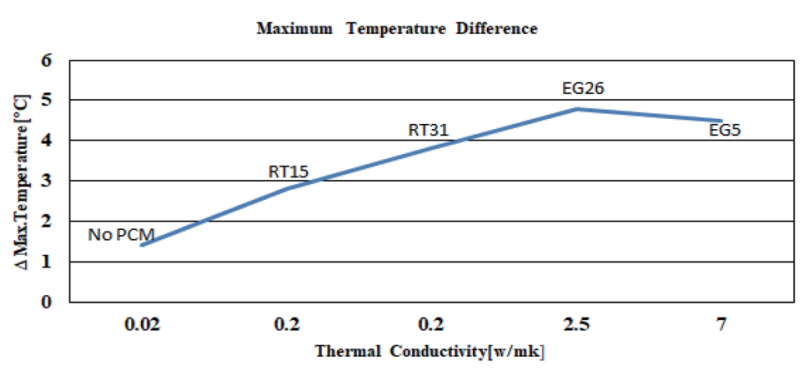

(a)

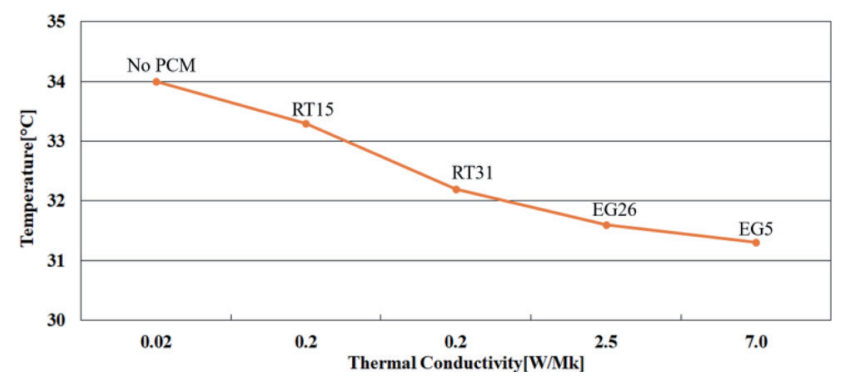

(b)

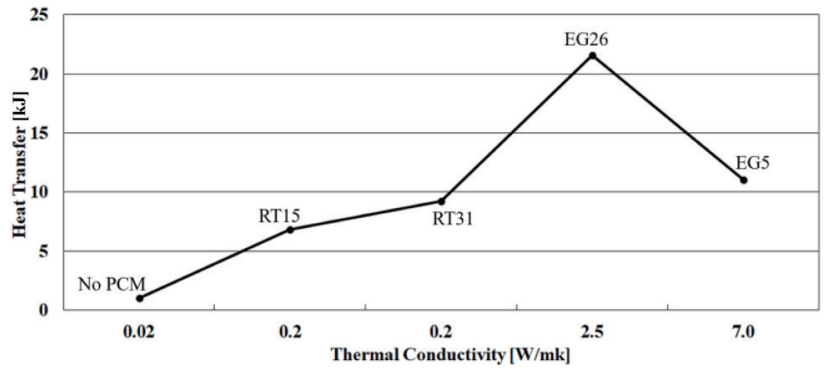

(c)

Fig. 9. (Color online) (a) Maximum temperature difference in PCMs, (b) maximum temperatures obtained with and without PCMs, and (c) heat transfer in batteries with and without PCMs. 
Table 4

Thermal performance of proposed PCMs under load test conditions.

\begin{tabular}{|c|c|c|c|c|c|c|c|}
\hline \multicolumn{3}{|c|}{ Load } & \multirow{2}{*}{$\begin{array}{c}\text { Without PCM } \\
\left({ }^{\circ} \mathrm{C}\right)\end{array}$} & \multicolumn{4}{|c|}{ Temperatures of Batteries with PCMs } \\
\hline Voltage (V) & Current (A) & Power (W) & & $\mathrm{RT} 15\left({ }^{\circ} \mathrm{C}\right)$ & RT31 $\left({ }^{\circ} \mathrm{C}\right)$ & $\mathrm{EG} 26\left({ }^{\circ} \mathrm{C}\right)$ & EG5 $\left({ }^{\circ} \mathrm{C}\right)$ \\
\hline 14 & 10.8 & 151.2 & 26.1 & 26.1 & 26.1 & 26.7 & 26.2 \\
\hline 12.2 & 10.2 & 124.4 & 27.3 & 27.0 & 26.5 & 27.2 & 26.5 \\
\hline 7.4 & 6.3 & 46.6 & 28.8 & 27.9 & 27.1 & 27.5 & 27.1 \\
\hline 5.5 & 4.5 & 24.8 & 30.5 & 28.9 & 27.6 & 27.7 & 27.5 \\
\hline 4.4 & 3.6 & 15.8 & 33.0 & 30.4 & 28.5 & 28.2 & 28.0 \\
\hline 3.3 & 2.7 & 8.9 & 35.9 & 32.5 & 31.3 & 30.5 & 30.7 \\
\hline
\end{tabular}

Table 5

Thermal performance of proposed PCMs.

\begin{tabular}{lccccccc}
\hline PCM & $\begin{array}{c}\text { Thermal } \\
\text { conductivity } \\
(\mathrm{W} / \mathrm{mK})\end{array}$ & $\begin{array}{c}\text { Melting } \\
\text { point }\end{array}$ & \multicolumn{2}{c}{ Maximum battery temperature } & Experiment & Simulation \\
\cline { 5 - 7 } & $\left({ }^{\circ} \mathrm{C}\right)$ & Exp. without & PCM $\left({ }^{\circ} \mathrm{C}\right)$ & PCM $\left({ }^{\circ} \mathrm{C}\right)$ & $\begin{array}{c}\text { Simulation } \\
\text { with PCM }\left({ }^{\circ} \mathrm{C}\right)\end{array}$ & $\Delta T\left({ }^{\circ} \mathrm{C}\right)$ & $\Delta T\left({ }^{\circ} \mathrm{C}\right)$ \\
\hline RT15 & 0.2 & 15.0 & 35.9 & 32.5 & 33.3 & 3.4 & 2.6 \\
RT31 & 0.2 & 31.0 & 35.9 & 31.3 & 32.2 & 4.6 & 3.7 \\
EG5 & 7.0 & 5.0 & 35.9 & 30.7 & 31.6 & 5.2 & 4.3 \\
EG26 & $\mathbf{2 . 5}$ & $\mathbf{2 6 . 0}$ & $\mathbf{3 5 . 9}$ & $\mathbf{3 0 . 5}$ & $\mathbf{3 1 . 3}$ & $\mathbf{5 . 4}$ & $\mathbf{4 . 6}$ \\
\hline
\end{tabular}

The thermal performance of the proposed batteries with PCMs during the experiment is shown in Table 4 . The initial battery temperature was $26.1^{\circ} \mathrm{C}$ before starting the discharge, and the initial voltage of the batteries was $14 \mathrm{~V}$. After $30 \mathrm{~min}$ of battery discharge up to $3.3 \mathrm{~V}$, the temperature of the battery without a PCM increased to $35.9^{\circ} \mathrm{C}$, whereas those of the batteries with RT15, RT31, EG26, and EG5, were recorded as 32.5, 31.3, 30.5, and $30.7{ }^{\circ} \mathrm{C}$, respectively. From the experimental results, we observed that among various types of PCMs, composite expanded graphite PCMs can be used to control the battery temperature to below $30.5^{\circ} \mathrm{C}$. The thermal performance of the proposed PCMs is given in Table 5.

As indicated in Ref. 17, the RT44HC/EG PCM has a high thermal conductivity of 7.85 $\mathrm{W} / \mathrm{mK}$. For the battery without a PCM, its temperature reached $46.3{ }^{\circ} \mathrm{C}$, but with a $\mathrm{PCM}$, its temperature was controlled to $36.3{ }^{\circ} \mathrm{C}$; hence, the maximum temperature difference $\Delta T$ obtained was $7.0^{\circ} \mathrm{C}$. Huang et al. ${ }^{(21)}$ concluded that the thermal conductivity of PCMs ranges from 1 to $3 \mathrm{~W} / \mathrm{mK}$, with a good decrease in temperature $\Delta T$ of $6.7^{\circ} \mathrm{C}$ being observed, but when the thermal conductivity increased from 7 to $15 \mathrm{~W} / \mathrm{mK}$, they observed no significant changes in temperature drop and only a temperature change of $0.31-0.66^{\circ} \mathrm{C}$ was seen.

Hence, in this research, expanded graphite materials with low melting points in the range of $5-26{ }^{\circ} \mathrm{C}$ yielded better results, and a maximum temperature difference of $5.4{ }^{\circ} \mathrm{C}$ was obtained with EG26.

\section{Conclusion}

The temperature distribution and thermal performance of PCMs in batteries were examined in detail in this study using a lithium polymer pouch battery with $3.7 \mathrm{~V} / 16 \mathrm{Ah}$ at different discharge rates and other various conditions, such as practical load conditions. The results 
provided data that satisfied the design specifications and enabled the control of battery temperature under safe operating conditions. The conclusions obtained from the experimental results are summarized as follows.

- The sensors used to monitor the temperatures of batteries enabled the detection of the maximum and control temperatures of batteries with selected PCMs.

- The maximum battery surface temperature reached $35.9^{\circ} \mathrm{C}$ during discharge under different load conditions without PCMs.

- EG26 in the simulation showed that the temperature of the battery with load was $31.3{ }^{\circ} \mathrm{C}$. However, without PCMs, the battery surface was $35.9^{\circ} \mathrm{C}$. Hence, the maximum temperature difference was $4.6^{\circ} \mathrm{C}$. This means that the temperature of the battery decreased owing to the high thermal properties of EG26. The experimental results obtained with EG26 showed that the battery surface temperature was $30.5^{\circ} \mathrm{C}$, whereas without EG26, the battery surface temperature was $35.9^{\circ} \mathrm{C}$. A difference of $5.4^{\circ} \mathrm{C}$ was observed with EG26.

- The simulation results are in agreement with the experimental results with a deviation of $0.8-1{ }^{\circ} \mathrm{C}$.

- Among all the selected PCMs, EG26 best controlled the battery temperature.

- Hence, we recommend EG26 as the best PCM for use in the BTMS.

- In the future, we will apply this effective battery thermal management to a $6 \mathrm{~kW}$ battery module.

\section{Acknowledgments}

This work was supported by the Korea Ministry of Trade, Industry and Energy, under the grant "The development of high strength lightweight aluminum battery package and PCMBTMS for high safety and battery efficiency improvement of electrical vehicle".

\section{References}

1 P. Satyam, I. Dincer, M. Agelin, R. Fraser, and M. Fowler: Int. J. Heat Mass Trans. 109 (2017) 1239. https://doi. org/10.1016/j.ijheatmasstransfer.2017.03.005

2 F. Leng, C. M. Tan, R. Yazami, and M. D. Le: J. Power Sources. 255 (2014) 423. https://doi.org/10.1016/ j.jpowsour.2014.01.005

3 H. Park: J. Power Sources. 239 (2013) 30. https://doi.org/10.1016/j.jpowsour.2013.03.102

4 S. Park and J. Dohoy: J. Power Sources. 227 (2013) 191. https://doi.org/10.1016/j.jpowsour.2012.11.039

5 X. H. Yang, S. C. Tan, and J. Liu: Energy Convers. Manage. 117 (2016) 577. https://doi.org/10.1016/ j.enconman.2016.03.054

6 Y. Azizi and S. M. Sadrameli: Energy Convers. Manage. 128 (2016) 294. https://doi.org/10.1016/ j.enconman.2016.09.081

7 B. Ye, M. R. H. Rubel, and H. Li: Appl. Sci. 9 (2019) 754. https://doi.org/10.3390/app9040754

8 A. Alrashdan, A. T. Mayyas, and S. Al-Hallaj: J. Mater. Process. Technol. 210 (2010) 174. https://doi. org/10.1016/j.jmatprotec.2009.07.011

9 W. Wu, G. Zhang, X. Ke, X. Yang, Z. Wang, and C. Liu: Energy Convers. Manage. 101 (2015) 278. https://doi. $\operatorname{org} / 10.1016 / j$.enconman.2015.05.050

10 T. Nomura, C. Zhu, S. Nan, K. Tabuchi, S. Wang, and T. Akiyama: Appl. Energy 179 (2016) 1. https://doi. org/10.1016/j.apenergy.2016.04.070

11 Y. Zhao, B. Zou, C. Li, and Y. Ding: Energy Procedia. 158 (2019) 4933. https://doi.org/10.1016/ j.egypro.2019.01.697 
12 G. Karimi, M. Azizi, and A Babapoor: J. Storage Mater. 8 (2016) 168. https://doi.org/10.1016/j.est.2016.08.005

13 Y. Lyu, ARM. Siddique, S. H. Majid, M. Biglarbegian, S. A. Gadsden, and S. Mahmud: Energy Rep. 5 (2019) 822. https://doi.org/10.1016/j.egyr.2019.06.016

14 J. Zhang, X. Li, F. He, J. He, Z. Zhong, and G. Zhang: Int. J. Photoenergy (2017). https://doi. org/10.1155/2017/2929473

15 Y. Lv, X. Yang, X. Li, G. Zhang, Z. Wang, and C. Yang: Appl. Energy 178 (2016) 376. https://doi.org/10.1016/ j.apenergy.2016.06.058

16 Z. Rao, Y. Huo, X. Liu, and G. Zhang: J. Energy Inst. 88 (2015) 241. https://doi.org/10.1016/j.joei.2014.09.006

17 Z. Ling, F. Wang, X. Fang, X. Gao, and Z. Zhang: Appl. Energy 148 (2015) 403. https://oi.org/10.1016/ j.apenergy.2015.03.080

18 Z. Wang, L. Xinxi, G. Zhang, Y. Lv, C. Wang, F. He, C. Yang, and C. Yang: RSC Adv. 7 (2017) 42909. https:// doi.org/10.1039/C7RA08181B

19 V. R. Voller, and C. Prakash: Int. J. Heat. Mass. Transfer. 30 (1987) 1709: https://doi.org/10.1016/00179310(87)90317-6

20 T. Talluri, T. H. Kim, and K J. Shin: Energies. 13 (2020) 507. https://doi.org/10.3390/en13030507

21 R. Huang, Z. Li, W. Hong, Q. Wu, and X. Yu: Energy Rep. 8 (2019). https://doi.org/10.1016/j.egyr.2019.09.060

\section{About the Authors}

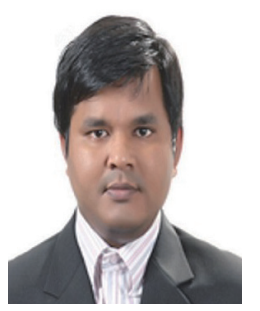

Amarnathvarma Angani is presently pursuing his Ph.D. degree under the guidance of Professor Kyoo Jae Shin of the Department of ICT Creative Design at Busan University of Foreign Studies (BUFS), Busan, South Korea. $\mathrm{He}$ received his master's degree in robotics from BUFS and his B. Tech degree in mechanical engineering from Jawaharlal Nehru Technological University, Kakinada (JNTUK), India, in 2014 and his diploma in automobile engineering from Andhra Polytechnic, Kakinada, India in 2007. He has four years of experience as a design engineer in InfoTech Enterprises from 2007 to 2011. His area of research is smart fish farms. He is also interested in controlling systems, fluid dynamics, thermodynamics, and design.

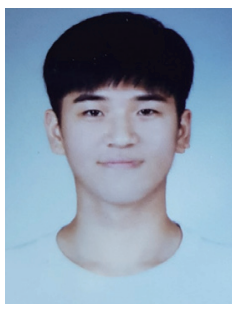

Euisong Kim is pursuing his master's degree in the Department of ICT Creative Design at BUFS. He received his bachelor's degree in robotics engineering from BUFS in 2019.

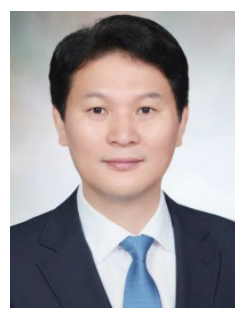

Kyoo Jae Shin is a professor in the Department of Intelligent Robot Science at BUFS. He is the director of the Future Creative Science Research Institute in BUFS. He received his B.S. degree in electronics engineering in 1985 and his M.S degree in electrical engineering in 1988 from Cheonbuk National University (CNU), and his Ph.D. degree in electrical science from Pusan National University (PNU) in 2009. Dr. Shin was previously a professor of the Navy Technical Education School. He is the main director of research associates of the dynamic stabilization system in Dusan Defense Weapon 
Research Institute. He has also studied and developed a fish robot, a submarine robot, an automatic drug spraying robot in a glass room, an automatic milking robot using a manipulator, a personal electrical vehicle, a smart accumulated aquarium using a heat pump, a solar tracking system, a 3D hologram system, and a gun/turret stabilization system. He is interested in developing intelligent robots, image signal processing application systems, smart farms, and aquariums using new energy and IoT technology. 